\title{
Four-Stage DEA Efficiency Evaluations: Financial Reforms in Public University Funding
}

\author{
G. Thomas Sav \\ Correspondence: G. Thomas Sav, Department of Economics, Raj Soin College of Business, Wright State \\ University, Dayton, OH 45440, USA. Tel: 1-937-775-3070. E-mail: tom.sav@wright.edu
}

Received: November 2, 2012

Accepted: November 14, 2012

Online Published: November 28, 2012

doi:10.5539/ijef.v5n1p24

URL: http://dx.doi.org/10.5539/ijef.v5n1p24

\begin{abstract}
Financial reforms in U.S. public higher education are well underway and are progressively replacing university enrollment based funding formulas with performance based models driven, in part, by graduation rates. Doing so, however, fails to account for the internal resource constraints and managerial efficiencies associated with production. Moreover, graduation rates are affected by external factors beyond the control of university decision-makers. This paper addresses these issues and uses a four-stage data envelopment analysis (DEA) model to evaluate university graduation rate performance. The four-stage DEA efficiencies correct for both environmental and statistical noise effects on university operations. Efficiency estimates control for the friendliness of the higher education operating environments as measured by differences in public financial support and educational quality. The results indicate that while universities are favorably efficient according to single stage estimates, additional efficiency gains of about three percentage points arise after accounting for good and bad fortune and external environmental effects. The number of efficient universities is found to more than double, thereby indicating significant shifts in the efficiency rankings of universities. Yet, better quality data is needed and should be forthcoming as universities and states gain greater experience with the implementation of performance based funding and ties to student success.
\end{abstract}

Keywords: DEA, four-stage, efficiency, finance, universities

\section{Introduction}

Financial reforms in U.S. public higher education are increasingly tying portions of university funding to student success outcomes, including university degree completion rates. In breaking with traditional student enrollment driven funding models, more than half of the U.S. state controlled public higher education systems have implemented or experimented with some form of performance based funding for allocating tax appropriated dollars (Miao, 2012). Although half of those states abandoned their early funding experiments, the American Association of State Colleges and Universities reports that "boosting college completion rates has led to a national productivity agenda for higher education" and a re-emergence in linking public university financing to student completion rates (Harnisch, 2011). More recently, four states are expected to allocate between five and eighty percent of state appropriated funding based on different performance measures, including degree completions. There are only fifteen states that have no formal activity related to a possible transition to performance based funding. In part, the re-emergence has been stimulated by a post-global financial crisis interest in public management reforms combined with specific concerns related to rising tuition costs and reports that only half of bachelor degree pursing students successfully obtain a college credential (Crellin, et al., 2011).

Using graduation rates to evaluate university performance, however, fails to account for the efficiency with which universities produce student success. That efficiency depends upon the quantity and quality of university resources and internal managerial performance in the allocation of those resources. In this regard, data envelopment analysis (DEA) has been long regarded as the standard non-parametric tool for evaluating operating efficiencies. And although a recent review puts the number of published DEA research papers at 4000 (Emrouznejad, et al., 2008), fewer than 20 studies have applied DEA, in one form or another, to higher education (Sav, 2012). Yet, standard DEA evaluations of university efficiencies are also misleading in that they neglect to account for external environmental factors that affect performance but are beyond the control of university decision makers. In practice, some universities operate in more friendly environments that offer greater financial support for education and better prepare students for success in higher levels of education. Other universities are 
compelled to operate in more unfriendly environments. To correctly evaluate university efficiencies in producing student graduation successes, adjustments must be made for the differential advantages and disadvantages created by external environments. To date, that has not been done in any DEA evaluations of university operating efficiencies and, therefore, establishes the basis for the present paper.

The paper provides efficiency estimates of U.S. public universities in producing baccalaureate degrees. The Fried et al. (2002) multistage DEA adjustment model is applied to a sample of 227 Carnegie classified master level universities. Using stochastic frontier analysis (SFA), the model extends the Fried et al. (1999) environmental adjustment methodology so as to include the additional adjustment for statistical noise. Thus, in the context of the current inquiry, universities efficiency estimates are adjusted for the uncontrollable good and bad fortunes that fall upon universities, as well as, the friendly and unfriendly external environmental effects. Three variables are used to adjust for environmental effects. These include differences in financial support, student academic preparedness, and educational quality. The empirical analysis provides first stage DEA efficiency estimates absent of those effects. Second stage SFA estimates are provided and used in a third stage input adjustment process. Repeating the DEA with the revised inputs produces the final stage university efficiencies adjusted for environmental and noise effects. The results indicate the importance of making such adjustments before evaluating the graduation rate performance of universities. The adjustment process increases overall university efficiencies and improves the efficiency rank order for the majority of universities.

The next section of the paper provides details of the methodology, starting with the single stage DEA model and expanding that to the development of the full environmental and noise adjustment model. Included is an overview of the empirical literature. That is followed by an explanation of the data sources and variables, a section presenting the empirical results by DEA stage, and a final section of discussion.

\section{Methodology}

The evaluation of university operating efficiencies will begin with the variable returns to scale (VRS) DEA model developed by Banker, et al. (1984). The analysis will then proceed incrementally to consider extensions of that model to include effects of environmental factors on efficiency estimates and then the additional need to purge statistical noise from the evaluations. The empirical focus will be on the efficiency with which universities successfully graduate students. The output $(y)$ will be the university graduation rate for undergraduate students. Given the declines in state funding of public universities, it is appropriate to choose an input oriented DEA approach to the efficiency evaluations. That is, over many years and especially since the budget cuts imposed by the global financial crisis, public universities are asked to produce the same or more with less. In addition, preliminary tests produced insignificant differences between the input vs. an output oriented evaluations. That is in general support of the conclusions offered by Coelli (1996) and Coelli and Perelman (1996) that orientation will usually have little effect on efficiency estimates.

\subsection{Single Stage, First Stage DEA}

We begin with each of $k=1, \ldots, N$ universities producing $y$ through the employment and allocation of $x_{i}$ inputs, $i=1, \ldots . I$. Ideally, university management has full control over these inputs. Using standard notation (e.g., Cook and Zhu, 2008) and denoting the university under evaluation by the subscript "o", the linear programing problem for the first stage DEA under consideration is

$$
\begin{aligned}
& \min _{\theta, \lambda} \theta, \text { subject to: } \\
& \theta x_{i 0} \geq \sum_{k=1}^{N} \lambda_{k} x_{k i} \\
& \sum_{k=1}^{N} \lambda_{k} y_{k} \geq y_{0} \\
& \sum_{k=1}^{N} \lambda_{k}=1, \quad \lambda_{k} \geq 0
\end{aligned}
$$

where the $\lambda$ are weights or measures of intensity levels for universities. Relaxing the last constraint, results in the original constant returns to scale (CRS) DEA model due to Charnes, et al. (1978). In the empirical implementation, the $x_{i}$ inputs number seven in total and are explained in detail in the data section of the paper. The optimization process results in the evaluation of the operating performance of each university such that $0 \leq \theta \leq 1$. Universities evaluated as efficient units, $\theta=1$, lie on the frontier and envelop inefficient units, $\theta<1$.

The efficiency performances obtained in this stage of the DEA can be attributed to three combined effects: (1) differences in the perspicacity of university management in making decisions over the employment and allocation of institutional resources, (2) random events that impose harm such as tsunamis and terrorism or bestow good fortunes such as unexpected philanthropy, and (3) differences in the external operating 
environments in which universities are positioned through their founding charters. Operating environments can differ in that some public universities operate in states within the U.S. that are less higher education friendly and less supportive in valuing higher education relative to other states. For example, differences exist in higher education government appropriated funding gathered through the tax mechanism. Consequently, DEA efficiency scores obtained without accounting for environmental effects would not be comparable for the same managerially competent universities operating in unfriendly state environments relative to those operating in friendly state environments. If resources could be adjusted so as to endow universities positioned in unfriendly states with the additional resources necessary to correct for the differential friendlessness, then the subsequent operating efficiencies could be equal for the same managerially competent universities. And, of course, after the process of resource adjustment, universities obtaining lower efficiency scores could no longer lay claim to hardships imposed by their external environment relative to their counterparts operating in other states.

\subsection{Environmental Adjustment}

Fried, Schmidt, and Yaisawarng (1999), hereafter FSY, offer a four stage methodology for making resource adjustments to account for effects of external operating environments and, therefore, isolate the performance inefficiency due to management. The adjustment occurs by first determining how external conditions affect the surplus use of inputs, i.e., the total input slacks $x_{i}-\sum \lambda x \geq 0$ from the first stage DEA. Allowing the external environment to be defined by a set of $\mathrm{z}$ environmental variables, a second stage econometric specification is used to estimate

$$
s_{i}^{k}=f_{i}\left(z_{i}^{k}, \beta_{i}, \varepsilon_{i}^{k}\right)
$$

where the dependent variables are the input slacks, the $\beta$ are coefficients to be estimated, and $\varepsilon$ represents the error term. FSY employ a Tobit regression for the estimation, although Simar and Wilson (2011) present clear arguments against employing Tobit regression in any second stage DEA approaches. In the third stage, estimated coefficients are used to predict input slacks for each university's input. The original inputs are subsequently adjusted as follows:

$$
x(\operatorname{adj})_{i}^{k}=x_{i}^{k}+\left(\max ^{k}\left(\hat{s_{i}}\right)-\hat{s}_{i}^{k}\right)
$$

where the $x(a d j)$ are the adjusted inputs and the " $\wedge$ " denotes estimated slacks. The fourth and final stage is the implementation of the originally specified DEA with the adjusted inputs replacing the original observations. The efficiency estimates obtained in this final process are free of environmental effects. Therefore, any detection of inefficiency can be credited to the internal decision-making of university management combined, however, with the possible impact associated with random effects. Neglect of these latter effects is, therefore, a shortcoming of the FSY model.

\subsection{Environmental and Noise Adjustment}

Within a matter of three years, Fried, Lovell, Schmidt, and Yaisawarng (2002), hereafter FLSY, extend the FSY model to include the additional adjustment for statistical noise. As declared by FLSY, their model is a three stage approach but in practice it can be staged in four steps and, therefore, for present comparative purposes it will be referenced as a four stage model. Unlike the FSY adjustment, the FLSY second stage requires a SFA specification where the error term is composed of managerial inefficiency $(u)$ and statistical noise $(v)$. For their proposed cost frontier, the second stage implementation is

$$
s_{i}^{k}=f_{i}\left(z_{i}^{k}, \beta_{i}\right)+v_{i}+u_{i}
$$

where $v$ is normally distributed with zero mean and standard deviation $\sigma_{v}^{2}$ and the $u \geq 0$ is normally distributed with mean $\mathrm{u}$ and standard deviation $\sigma_{u}^{2}$. Of course, for the production frontier of interest in the present paper, only minor modifications are necessary as $u \leq 0$. Estimation proceeds with a maximum likelihood method and reparameterization such that $\sigma^{2}=\sigma_{v}^{2}+\sigma_{u}^{2}$ and $\gamma$ is estimated by $\sigma_{u}^{2} /\left(\sigma_{v}^{2}+\sigma_{u}^{2}\right)$. Thus, for a given input slack, if $\gamma$ equals the value of (zero) one, then there is no (managerial inefficiency) statistical noise. As in the FSY methodology, the third stage requires adjustment to the originally observed inputs. In this FLSY extension, however, inputs are adjusted upwards so as to account for units operating in not only advantageous environments but also in climates showered with good fortune. The more demanding FLSY adjustment proceeds as follows:

$$
x(\operatorname{adj})_{i}^{k}=x_{i}^{k}+\left(\max f\left(z_{i}^{k}, \hat{\beta}_{i}\right)-f\left(z_{i}^{k}, \hat{\beta}_{i}\right)\right)+\left(\max \left(\hat{v}_{i}^{k}\right)-\hat{v}_{i}^{k}\right)
$$


where the $v_{i}$ are estimated by

$$
\hat{E}\left[v_{i} \mid v_{i}+u_{i}\right]=s_{i}-z_{i} \hat{\beta}-\hat{E}\left[u_{i} \mid v_{i}+u_{i}\right]
$$

all of which are performed for each university. Once again, the fourth and final stage is a repeat of the input oriented DEA but with the adjusted inputs replacing the original observations.

\subsection{Empirical Literature}

FSY applied the four stage adjustment model to a 1993 sample of hospital-affiliated nursing homes. Control for environmental climate included nursing home location, ownership structure, and bed size. The mean pre vs. post adjusted efficiencies were approximately 0.52 and 0.68 , respectively. In addition, the number of efficient home declined by about $33 \%$. The decline in efficient homes led to the conclusion that the larger number of efficient units in the single stage DEA was due to their enjoyment of favorable operating environments. FLSY use the same sample and variables in employing their environmental and noise adjustment model. With the added noise adjustment, the mean efficiency for nursing homes increased from 0.52 to approximately 0.91 . In contrast to the FSY results, however, the number of efficient homes increased and did so rather dramatically by more than twofold. Thus, many homes received low first stage efficiency evaluations due to the combined effects of bad luck and poor operating environments. In a more limited framework, four stage DEA adjustment models have also been applied to energy production (Hu, et al., 2011) and nonprofit social service organizations (Medina-Borja and Triantis, 2011). However, a literature review reveals that only one study exists with respect to an application pertaining to education. Cordero-Ferrera, et al. (2008) use the more limited FSY environmental adjustment to evaluate the efficiencies of 80 Spanish public schools operating during 2001-02 school year. Using two outputs and only two inputs along with three environment variables, they report an efficiency improvement over a single stage DEA of approximately $3.7 \%$ with about $58 \%$ of the schools achieving efficiency increases greater than $5 \%$.

To date, their does not appear to be any higher education DEA studies that have followed in the footpaths of three or four stage DEA adjustment models. However, there are at least 18 single stage DEA studies that have examined the performance aspects of academic departments or programs in select universities and the efficiencies of universities in different countries. These studies are reviewed in Sav (2012 a). Only one of the studies, however, focused on the interest of the present paper in estimating university level efficiencies related to the production of student academic success. That study by Agasisti and Johnes (2009), however, includes both bachelor and master student graduations along with external research funding in a three output, five input DEA. Thus, it is not possible to disentangle their three outputs and examine only graduation rate outcomes. For their 2003-04 academic year samples of Italian $(\mathrm{N}=57)$ and English $(\mathrm{N}=127)$ universities, the overall efficiency estimates varied from approximately 0.81 under CRS to 0.89 under VRS. In a more recent study, Sav (2012 b) uses graduation rates as a single output along with ten inputs in DEA estimates for 198 private universities and 216 public universities operating in the U.S. over the 2005-09 academic years. For the public university sector, mean efficiencies varied from 0.57 under CRS to 0.65 under VRS. Private universities, considered to be more academically selective in regards to student admissions, had graduation CRS and VRS efficiencies of 0.60 and 0.71 , respectively. In either sector, the budgetary cuts accompanying the global financial crisis could not be sorted out and may be, in part, responsible for the lower efficiencies when compared to the Agasisti and Johnes (2009) findings. In any event, neither of these single stage studies accounted for possible impacts on university operating efficiencies that could be due to differences in external environments, be they academic, regulatory, or financial. That absence establishes the need and motivation for the present study.

\section{Data}

\subsection{Sources}

University level data are drawn from the U.S. National Center for Education Statistics, Integrated Postsecondary Data System (IPEDS). The sample includes Carnegie classified master level universities offering baccalaureate degrees and involved in graduate program education to a limited extent. The higher level research intensive-doctoral granting classified universities are not evaluated due to the fact that they tend be more selective in undergraduate admission standards and engage heavily in professional education, including law, medical, etc. for which separate input data are unavailable in a national data base. Since the methodology is based in both DEA and SFA, four academic years of data, 2005-09, are averaged so as to smooth university production (e.g., Ruggiero, 2007). From IPEDS, the output is the university's graduation rate defined as baccalaureate degree completion within $150 \%$ of standard time. On the input side, it was possible to construct 
seven variables believed to capture the effect on graduation rates due to institutional characteristics and managerial decision-making. For each state in the U.S., there are three higher education environmental variables obtained from the National Center for Higher Education Management Systems (NCHEMS) data base. Merging the IPEDS and NCHEMS data produced a useable sample of 227 public universities operating in 42 states. A summary of the variables along their descriptive statistics is presented in Table1 and is discussed in the following.

Table 1. Output, Inputs, and Environmental Variables

\begin{tabular}{lllll}
\hline & Mean & Std. Dev. & Minimum & Maximum \\
\hline $\begin{array}{l}\text { Output } \\
\text { Grad-Rate, \% }\end{array}$ & 45.17 & 13.19 & 14.01 & 86.14 \\
Inputs & & & & 31673 \\
Enroll-Size, \# & 8610.16 & 5510.76 & 1136 & 1240 \\
Prepared, \# & 895.63 & 85.95 & 706 & 73 \\
Low-Inc, \% & 33.00 & 14.43 & 8 & 7116 \\
Post-Bacc, \# & 1600.37 & 1341.26 & 20 & 950 \\
Faculty, \# & 342.21 & 185.93 & 59 & 4856.99 \\
Student-Exp, \$ & 1403.00 & 590.68 & 418.38 & 54.02 \\
Instruct-Exp, \$ & 35.94 & 6.40 & 19.48 & 10294.00 \\
Envirnonments & & & & 271.40 \\
Govt-Support, \$ & 6894.18 & 1123.42 & 3505.00 & 3.35 \\
Sch-Quality, \# & 190.03 & 39.62 & 125.40 & 0.13 \\
Import-Export, \# & 1.15 & 0.56 & & \\
\hline
\end{tabular}

\subsection{1nput Variables}

In one form or another, the input variables have been used in previous DEA or SFA higher education studies and, therefore, require only brief explanations (see Sav, 2012b and 2012c for a review of such studies). The first three inputs in Table 1 are student-institution related. The first (Enroll-Size) measures the size of the institution based on the total undergraduate student enrollment. Conventional wisdom holds that larger institutions are less individually student oriented and would, therefore, produce lower rates of student academic success, ceteris paribus. Academic preparation of students presents an increasing issue of concern in higher education and is measured here by student SAT (Scholastic Aptitude Test) standardized admission test scores (Prepared). Low-Inc is the percentage of enrolled students on low-income federal government grants and is intended to capture the financial difficulties of student retention but also the possibility of arriving from low income, underfunded primary and secondary school districts. Also included is the total enrollment of students at the post baccalaureate level (Post-Bacc) as a measure of a university involvement in graduate level education. The data is unrefined data, so this could include students enrolled in traditional graduate programs as well as non-traditional certification or re-training type programs. Greater involvement in graduate education could either enhance or detract (given resource constraints) from a university's focus on undergraduate education. The current literature provides no a priori insights into the effect on undergraduate student success as could be effected by graduate programs or graduate student presence. The last three inputs in Table 1 would generally be expected to have positive effects on a university's overall success in graduating students. That includes the positive effects of faculty employment (here measured by teaching faculty employment and excluding administrative faculty, e.g., department chairs and deans), the allocation of university expenditures in providing student services, and the allocation of university resources in supporting academic instruction.

\subsection{Environmental Variables}

Three environmental variables are included to capture different aspects of the external operating environment pertaining to the states in which public universities are chartered, regulated, and funded. The Govt-Support variable is the state and local government contribution to public university operating expenses per full-time equivalent student. States (i.e., constituents) that place a greater value on higher education and, therefore, are more educationally supportive in offering their tax dollars are deemed more friendly in creating an operating environment for public universities. As noted in Table 1, that support varies across states from a low of approximately $\$ 3,500$ to over $\$ 10,000$ per student. In addition, it is necessary to consider the quality of education delivered throughout the primary-secondary school experience as that affects the academically prepared pool of 
students for university admissions. Thus, a school quality (Sch-Quality) variable is included as a means of controlling for the primary-secondary environment facing universities. The variable is the number of high school students per 1,000 that score at the $80^{\text {th }}$ percentile and above on either the SAT or ACT (American College Testing) tests. The better the Sch-Quality, the better the environment for producing higher education graduates. However, students attending public universities do not always attend the same resident-state institution. Inter-state differences in tuition, program offerings, and overall university quality, among other things, drive students across state borders. College choices and migration of college-going students is beyond the scope of the present paper. Rather, it is assumed here that the total effect of a state's higher education friendlessness-cost-quality combinations influence its ability to keep resident students and attract students from other states. The net effect is measured by the variable Import-Export that is calculated as the number of college freshman imported from other states relative to the number of resident freshman attending college out-of-state. An Import-Export greater (less) than one is assumed to be indicative of a more friendly (unfriendly) higher education environment.

\section{Results}

\subsection{First Stage DEA}

The first stage DEA results are offered in Table 2 for both constant and variable returns to scale estimates. With the presence of scale inefficiencies the lower CRS efficiencies indicate that universities are approximately $71 \%$ efficient on average. The VRS mean efficiency is $94 \%$ and is comparable to, for example, the mean efficiency of approximately 90\% for Italian and English institutions (Agasisti and Johnes, 2009), although direct comparisons are questionable given the differences in sampling of academic years, model specifications, and the inter-country differences in the regulation and financing of higher education. In the present evaluations, the minimum efficiency under CRS is surprisingly low at 0.239 . Under VRS, the minimum appears more reasonable at $80 \%$. By the same token, only 15 universities are efficient under CRS but that rises to 48 or more than $20 \%$ of all universities under VRS. With regard to the returns to scale, none of the universities are found to operate under decreasing returns to scale. Increasing returns prevails among a full $86 \%$ of the institutions.

Table 2. DEA First Stage Unadjusted Efficiencies

\begin{tabular}{llll}
\hline & CRS & VRS & Scale \\
\hline Mean & 0.713 & 0.944 & 0.754 \\
Median & 0.710 & 0.945 & 0.762 \\
Minimum & 0.239 & 0.788 & 0.259 \\
Maximum & 1 & 1 & 1 \\
Std. Dev. & 0.166 & 0.046 & 0.162 \\
Efficient, \# & 15 & 48 & \\
Efficient, \% & $6.61 \%$ & $21.15 \%$ & \\
Decreasing & & & $0 \%$ \\
Constant & & & $6.07 \%$ \\
Increasing & & & $85.83 \%$ \\
\hline
\end{tabular}

\subsection{Second Stage SFA and Third Stage Adjustments}

Table 3 reports the second stage SFA estimates. Following FLSY, the estimates are based on the half normal specification of the inefficiency component. The SFA slack estimates are presented for four of the seven inputs, including Enroll-Size, Prepared, Post-Bacc, and Faculty. Tests on the slack estimates for Low-Inc, Student-Exp, and Instruct-Exp rejected the frontier specification and the OLS results produced adjusted $R^{2} \mathrm{~s}$ that did not exceed 0.05 . Thus, it was determined that no adjustments were to made with regard to these three inputs. But for the four significant slack estimates, managerial inefficiency is significant in determining the excess use of inputs. In fact, in the Enroll-Size and Faculty estimates, the gamma estimates are very close to indicating that all of the slack is due to management. That inefficiency is weaker but statistically significant in the Prepared and Post-Bacc slacks where statistical noise, therefore, carries relatively greater impact. The results also indicate that the external environment affects input slacks. The coefficients for all three environmental variables are consistently negative in the Enroll-Size and Faculty slacks, thereby suggesting that greater government funding support, better primary and secondary schools, and a state's ability to be a net importer of college-going choice is consistent with a friendly or favorable higher education environment. The better those environmental conditions, 
the less excess there is of student enrollment and faculty employment at the university level. In the remaining two slack estimates, the environmental effects are weak and only the Sch-Quality effect could be considered significant but only if the level of significance was moved to approximately $20 \%$. But again, gamma, along with the likelihood ratios, is statistically significant and supports the frontier specification.

Table 3. SFA Estimates of DEA Input Slacks for Environmental Variables

\begin{tabular}{lllll}
\hline & Enroll-Size & Prepared & Post-Bacc & Faculty \\
\hline Constant & $* 32.498$ & 0.157 & $* 10.801$ & $* 15.787$ \\
& $(0.666)$ & $(0.266)$ & $(5.381)$ & $(5.508)$ \\
Govt-Support & $*-1.653$ & 0.009 & 0.188 & $*_{-} 0.768$ \\
& $(0.187)$ & $(0.029)$ & $(0.684)$ & $(0.400)$ \\
Sch-Quality & $*-1.585$ & $*_{-}-0.036$ & $*_{-} 0.810$ & $*_{-} 0.553$ \\
& $(0.225)$ & $(0.005)$ & $(0.328)$ & $(0.261)$ \\
Import-Export & $*-0.275$ & 0.007 & -0.087 & $*-0.207$ \\
& $(0.160)$ & $(0.009)$ & $(0.201)$ & $(0.113)$ \\
Sigma Sq. & $* 35.246$ & $* 0.015$ & $* 33.243$ & $* 14.848$ \\
& $(3.067)$ & $(0.001)$ & $(3.410)$ & $(0.552)$ \\
Gamma & $* 0.999$ & $* 0.980$ & $* 0.997$ & $* 0.999$ \\
& $(0.0003)$ & $(0.002)$ & $(0.002)$ & $(0.00007)$ \\
Likelihood & $*-566.54$ & $* 261.76$ & $*_{-} 571.11$ & $* 476.89$ \\
Likelihood Ratio & 108.828 & 214.598 & 32.819 & 57.763 \\
Max $s_{i}$ & 27138.35 & 1.042 & 1.47 & 171.03 \\
Mean $s_{i}$ & 13769.29 & 1.009 & 1.17 & 34.02 \\
Max $v_{i}$ & 27138.26 & 1.0032 & 1.0003 & 1.062 \\
Mean $v_{i}$ & 77.41 & 1.0003 & 1.0002 & 1.06 \\
\hline
\end{tabular}

Note: Asterisk denotes significance at the 10\% level and better. Max si ,vi are for Eq. (5) and are presented in original measurement units.

The stage two parameter estimates are used to predict university input slacks and determine the necessary values for performing the adjustments to observed inputs. The maximum and means from that the estimation process are reported in the lower portion of Table 3. These correspond to the maximums and means of the predicted slacks due to the environment and due to statistical noise. The means from the predicted results are consistently positive and indicate that, on average, unfriendly higher education environmental effects are present with regard to each of the four university inputs. Also, there is some good fortune at work as indicated by the presence of statistical noise.

\subsection{Final Stage DEA}

The final stage DEA estimates are based on the adjusted inputs and are given in Table 4. Compared to the first stage estimates, all university efficiency measures improve with the adjustments for education environmental effects and good or bad fortune. For both the CRS and VRS, the efficiency gain is a little over 0.03 or $3 \%$ points, e.g., the VRS efficiency increases from 0.944 to 0.976 . With the input adjustments in place, the median VRS efficiency is 0.995 , an increase of $5 \%$ points. With the scale inefficiencies present in the CRS estimates, there is not much movement in the minimum efficient university $(0.252$ from 0.239$)$. Under VRS, however, there is nearly a $7 \%$ point increase $(0.788$ to 0.856 ). Although these efficiency improvements are not as dramatic as those reported in the FLSY study of nursing homes, it must be noted that the initial DEA efficiency for those nursing homes started at a low of just over $50 \%$ (i.e., 0.522 ) in comparison to the present first stage university efficiencies of 94\%. Here, however, as with FLSY results, there is more than a $100 \%$ increase in the number of efficient universities; 108 vs. 48 . That, along with the mean, median, and minimum efficiency improvements, lends support to the notion that the efficiency with which universities can produce student graduates is affected by government funding and support of not only higher education, but also primary and secondary education in preparing students for college success. 
Table 4. Final Stage DEA Input Adjusted Efficiencies

\begin{tabular}{llll}
\hline & CRS & VRS & Scale \\
\hline Mean & 0.747 & 0.976 & 0.764 \\
Median & 0.756 & 0.995 & 0.774 \\
Minimum & 0.252 & 0.856 & 0.27 \\
Maximum & 1 & 1 & 1 \\
Std. Dev. & 0.167 & 0.033 & 0.163 \\
Efficient, \# & 21 & 108 & \\
Efficient, \% & $9.25 \%$ & $47.58 \%$ & \\
Decreasing & & & $0 \%$ \\
Constant & & & $8.50 \%$ \\
Increasing & & & $83.40 \%$ \\
\hline
\end{tabular}

University efficiency rankings can offer additional insights into the effects of the adjustments made for different operating environments. However, unlike the FLSY nursing home application with categorical environmental variables, presently there are three continuous environmental variables varying across 42 states. Thus, it is not practical to present all possible outcomes. From a more aggregate perspective, a comparison was made between the efficiency rankings based on the first stage unadjusted estimates and the rankings based on the final input adjusted efficiencies. The mean rank change was found to be 25.45, using the VRS estimates. The rank correlation was 0.78 . The aggregate effects of the adjustment process led to 171 universities improving their ranking, 9 universities losing ground, and 47 universities maintaining the same rank position. Note that the efficiency rankings are shifting simultaneously with a shift in the efficiency distribution, the latter being the effects as presented in Table 4.

In attempt to uncover how the adjustment process leads to rank changes for a given environmental effect, the Govt-Support environments are collapsed into three categories of funding levels and presented in Table 5 along with a decomposition of the rank changes.

Table 5. University Efficiency Rank Changes: Final vs. First Stage

\begin{tabular}{|c|c|c|c|c|c|}
\hline \multirow[b]{2}{*}{ Govt-Support (G) } & \multicolumn{4}{|c|}{ Efficiency Rank Changes ( $\Delta$ ) } & \multirow[b]{2}{*}{ Mean $\Delta$} \\
\hline & $N$ & $\Delta>0$ & $\Delta=0$ & $\Delta<0$ & \\
\hline $\begin{array}{l}\text { High } \\
(G>\$ 7,000)\end{array}$ & 111 & 84 & 24 & 3 & 41.13 \\
\hline $\begin{array}{l}\text { Medium } \\
\left(\$ 6,000 \leq_{\mathrm{G}} \leq \$ 7,000\right)\end{array}$ & 58 & 52 & 6 & 0 & 50.50 \\
\hline $\begin{array}{l}\text { Low } \\
(\mathrm{G}<\$ 6,000)\end{array}$ & 28 & 35 & 17 & 6 & 25.44 \\
\hline Total & 227 & 171 & 47 & 9 & 39.51 \\
\hline
\end{tabular}

Thus, 84 of the 111 universities operating in the highest government financial support environments experienced rank improvements following input adjustments. Rank improvements occurred with respect to 35 of the 58 universities housed in the lower support environments and for the 52 of the 58 universities in the categorized middle support environment. The problem, of course, is that it is not appropriate to attribute all of the university rank changes presented in Table 6 to adjustments for government financing environments. There are two other external environmental factors at work along with good and bad fortune coming into play. Unfortunately, given the large number of environmental combinations involved, it is impractical to present marginal effects for each possible combination. Somewhat of an artificial comparison is that shown in the last column of Table 6. The mean rank improvement for universities operating in the highest government funding category (41) is smaller in comparison to the mean rank improvement (50) in the less friendly mid government funded category.

\section{Discussion}

Changes in the financial landscape facing public universities are well underway and are placing future funding accountability on the ability to produce student academic success, including degree completion rates. While a focus on graduation rates breaks with conventional enrollment based funding, it falls short of traditional 
measures of economic efficiency to evaluate university performance. To investigate those efficiencies, this paper employed DEA and compares efficiency estimates obtained from single stage evaluations to four stage adjustments for both environmental and noise effects. The final stage non-parametric efficiencies rely on second and third stage SFA parametrically determined adjustments to university inputs. Thus, the efficiency adjustments occur on the basis of good and bad fortune falling upon universities as well as external factors affecting efficiency but beyond the control of university decision-makers. The latter are determined by state governing boards and legislators and end up as measures of differences in the government financial support of higher education, the college preparedness of high school graduates, and the quality of higher education as determined by the import and export of college going students.

The results indicate that the mean university efficiency improvement is on the order of $3 \%$ points, increasing from 0.944 in a single stage DEA evaluation to 0.976 when employing the FLSY (Fried et al., 2002) adjustment process for noise and environmental effects. Given that the present analysis is believed to be the first to apply the FLSY adjustment model to higher education, there does not exist a benchmark evaluation for comparison. For the nursing home results produced in the FLSY application the efficiency improvement over single stage DEA was 0.91 vs. 0.52 . Thus, the current university efficiency improvement is not as dramatic as that presented for nursing homes, suggesting greater managerial inefficiencies and more important environmental effects in that portion of the health care industry relative to higher education. Nevertheless, the smaller efficiency differential for universities does not diminish the need for and importance of the adjustment process when the stakes involve the allocation of millions of dollars of tax appropriated university funding. Moreover, a striking difference resulting from the adjustment process was found to be the increase in the number of efficient universities from 48 to 108 or more than a $100 \%$ increase. Thus, the combined evidence is supportive of both a positive shift in the efficiency distribution and a change in the efficiency ranking of universities. The latter would be of particular importance if any public university performance based funding model appropriately accounts for efficiency differences in delivering the academic success of students.

The analysis is not without its shortcomings, most of which have also plagued previous single stage DEA evaluations of higher education and pertain, in general, to issues associated with the quality of data. A particularly troublesome area relates to the absence of controls for variations in teaching quality. Here, as elsewhere, faculty employment had to be used to measure teaching inputs. The national data base does not provide any data related to teaching loads, grade distributions, or other information at the instructor level that could possibly proxy teaching quality. On the student input side, the analysis did include a measure of incoming student preparedness based on achievement test scores. However, for continuing students, the data did not permit any distinction between part-time and full-time student graduation rates or the effect on graduation due to student transfers between universities. There was an attempt to include some measure of the minority and ethnic composition of the student body but missing observations would have severely reduced the sample size. With respect to the variables used to measure external university environments, the major focus was at the state level. There are local environmental factors that likely affect university graduation success but escaped the analysis. For example, many master level universities draw the majority of their students from local markets, i.e., school districts. Those school districts can vary widely in quality and affect the student preparedness pool for university enrollments. There may also be some regional environmental variations associated with accrediting boards that need to be taken into account. We should expect a supply of better quality data as states and individual universities gain experience in the implementation of performance based financing that ties funding to student academic success. That data should benefit future research in investigating the efficiencies with which universities produce student academic success and, ultimately, graduations.

\section{References}

Agasisti, T., \& Johnes, G. (2009). Beyond frontiers: comparing the efficiency of higher education decision-making units across more than one country. Education Economics, 17(1), 59-79. http://dx.doi.org/10.1080/09645290701523291

Banker, R. D., Charnes, A., \& Cooper, W. W. (1984). Some models for estimating technical and scale inefficiencies in data envelopment analysis. Management Science, 30, 1078-1092. http://dx.doi.org/10.1287/mnsc.30.9.1078

Charnes, A., Cooper, W. W., \& Rhodes, E. (1978). 'Measuring the efficiency of decision making units. European Journal of Operational Research, 2(6), 425-444. http://dx.doi.org/10.1016/0377-2217(78)90138-8

Coelli, T. J., Rao, D. S. P., O'Donnell, C. J., \& Battese, G. E. (2005). An Introduction to Efficiency and Productivity Analysis. Springer, New York. 
Coelli, T. J., \& Perelman, (1996). A comparison of parametric and non-parametric distance functions: with application to European railways, CREPP Discussion Paper, University of Liege, Liege.

Cook, W. D., \& Zhu, J. (2008). Data Envelopment Analysis. Wade D. Cook and Joe Zhu.

Cordero-Ferrera, J., Pedraja-Chaparro, F., \& Salinas-Jimenez, J. (2008). Measuring efficiency in education: an analysis of different approaches for incorporating non-discretionary inputs. Applied Economics, 40(10), 1323-1339. http://dx.doi.org/10.1080/00036840600771346

Crellin, M., Aaron, D., Mabe, D., \& Wilk, C. (2011). Catalyst for completion: performance-based funding in higher education. New England Board of Higher Education, MA: Boston.

Emrouznejad, A., Parker, B. R., \& Tavares, G. (2007). Evaluation of research in efficiency and productivity: A survey and analysis of the first 30 years of scholarly literature in DEA. Socio-Economic Planning Sciences, 42(3), 151-157. http://dx.doi.org/10.1016/j.seps.2007.07.002

Freid, H. O., Schmidt, S. S., \& Yaisawarng, S. (1999). Incorporating the operating environment into a nonparametric measure of technical efficiency. Journal of Productivity Analysis, 12(3), 249-267. http://dx.doi.org/10.1023/A:1007800306752

Freid, H. O., Lovell, C. A. K., Schmidt, S. S., \& Yaisawarng, S. (2002). Accounting for envirnonmental effects and statistical noise in data envelopment analysis. Journal of Productivity Analysis, 17(1/2), 157-174. http://dx.doi.org/10.1023/A:1013548723393

Harnish, T. L. (2011). Performance-based funding: a re-emerging strategy in public higher education financing, American Association of State Colleges and Universities, Washington, D.C.

Hu, J., Lio, M., Yeh, F., \& Lin, C. (2011). Environment-adjusted regional energy efficiency in Taiwan. Applied Energy, 88(8), 2893-2899. http://dx.doi.org/10.1016/j.apenergy.2011.01.068

Medina-Borja, A., \& Triantis, K. (2011). Modeling social services performance: a four-stage DEA approach to evaluate fundraising efficiency, capacity building, service quality, and effectiveness in the nonprofit sector, Annals of Operations Research. http://dx.doi.org/10.1007/s10479-011-0917-0

Miao, K. (2012). Performance-based funding of higher education, Center for American Progress. Washington, D.C.

Ruggiero, J. (2007). A comparison of DEA and stochastic frontier model using panel data. International Transactions in Operations Research, 14(3), 259-266. http://dx.doi.org/10.1111/j.1475-3995.2007.00585.x

Sav, G. T. (2012a). Productivity, efficiency, and managerial performance regress and gains in united states universities: a data envelopment analysis. Advances in Management and Applied Economics, 2(3), 13-32. ISSN: 1792-7544 (print version), 1792-7552 (online)

Sav, G. T. (2012b). Frontier and envelopment evaluations of university graduation efficiencies and productivities: elements for performance based funding?. Problems and Perspectives in Management, 4, forthcoming.

Sav, G. T. (2012c). Cost efficiencies and rankings of ivy universities: stochastic panel estimates. International Journal of Economics and Finance, 4(3), 3-12. http://dx.doi.org/10.5539/ijef.v4n3p3

Simar, L., \& Wilson, P. W. (2011). Two-stage DEA: caveat emptor. Journal of Productivity Analysis, 36(2), 205-218. http://dx.doi.org/10.1007/s11123-011-0230-6 